\title{
Basic Principles of Science in Medical Education-Development and Implementation of a Two Week Introductory Track
}

\author{
Nico Vonneilich ${ }^{*}$, Hans-Hermann Dubben², Levente Kriston³, Andreas H. Guse ${ }^{4,5}$, \\ Olaf von dem Knesebeck ${ }^{1}$ \\ ${ }^{1}$ Department of Medical Sociology, University Medical Center Hamburg-Eppendorf, Hamburg, Germany \\ ${ }^{2}$ Department of Primary Medical Care, University Medical Center Hamburg-Eppendorf, Hamburg, Germany \\ ${ }^{3}$ Department of Medical Psychology, University Medical Center Hamburg-Eppendorf, Hamburg, Germany \\ ${ }^{4}$ Department of Biochemistry and Molecular Cell Biology, University Medical Center Hamburg-Eppendorf, \\ Hamburg, Germany \\ ${ }^{5}$ Medical Faculty, University Medical Center Hamburg-Eppendorf, Hamburg, Germany \\ Email: "n.vonneilich@uke.uni-hamburg.de
}

Received 10 February 2016; accepted 7 May 2016; published 10 May 2016

Copyright (C) 2016 by authors and Scientific Research Publishing Inc.

This work is licensed under the Creative Commons Attribution International License (CC BY).

http://creativecommons.org/licenses/by/4.0/

(c) (i) Open Access

\section{Abstract}

It has been argued that medical education lacks a specific focus on scientific skills and competencies. A recently developed compulsory introductory track on the basic principles of science in medicine was integrated into the medical curriculum at the University Medical Center in Hamburg, Germany. The curriculum of the two-week track included six lectures and six classes. All first term students of medicine participated on a mandatory basis. Data on student satisfaction were obtained in an online evaluation process. Content of the classes was reading and critical examination of scientific papers, searching and citing literature, discussion of ethical aspects in medical science and the presentation of scientific results. Lectures were held on the basic principles of the research process, types of epidemiological studies, ethical aspects in medical science and examples of scientific research in medicine. Evaluation showed high overall satisfaction among students. Our experiences and students' evaluation suggest that teaching science can be successfully implemented in the medical curriculum. This is one of the first successful implementations of teaching basic principles of science in medical curricula in Germany. We suggest to integrate different disciplines in the development and implementation process and to implement the introductory track early in the medical curriculum.

\footnotetext{
"Corresponding author.
} 
Keywords

Basic Principles of Science, Medical Education, Teaching Science

\section{Introduction}

Medicine relies on sound scientific research. Especially during the last decades, a growing importance of and a higher need for evidence based medicine (EBM) can be observed (Aronoff et al., 2010). Still, it is argued that medical education lacks a focus on scientific skills and competencies (Pawlina, 2009; Fischer \& Fabry, 2014; Spencer et al., 2008). A recent recommendation on the development of medical education in Germany by the German Council of Science and Humanities (Wissenschaftsrat) underlines this issue. The Council recommends a longitudinal integration of basic scientific skills in the medical curricula (German Council of Science and Humanities, 2014). Several medical faculties in Germany developed and implemented model medical degree programmes, meeting the expectations of the Council in different ways. Model medical degree programmes can be found in Berlin, Düsseldorf, Hamburg or in Hannover, among others. A core ability, among others, for future medical practitioners will be to find information, to assess the information's quality and to make evidence based decisions rather than to recall once learned facts, as knowledge in medical sciences keeps growing (Lawson Maclean et al., 2013; Grande, 2009; Smeeton, 1997). These abilities are needed in order to integrate EBM into everyday practice. Along these lines, it has been suggested that statistical and critical thinking in medical education should become an elementary part of medical education, since a basic understanding of statistics is of growing importance in everyday medical practice (Smeeton, 1997; Siegrist \& Giger, 2006).

Results of a critical review of different US and Canadian medical school curricula show that only few of these schools offer training on basic scientific skills and competencies during the clinical years and that this situation has not changed much since the 1980's (Spencer et al., 2008). "Exposure to basic science principles and appreciation for translational research are important to maintain the science of medicine, supporting a paradigm of integrative medical education” (Spencer et al., 2008: p. 663). Thus, a profound knowledge of science and basic scientific principles must form a basis of any curriculum of medicine (Grande, 2009; Norman, 2009). There is more to a good physician than being a professional in healthcare and an advocate of the patient's health: a good physician should also be a good scholar, as it has been proposed in the CanMEDS framework of the Royal College of Physicians and Surgeons in Canada (van der Lee et al., 2013).

Moreover, it has been suggested that training in scientific research and research skills might help to improve the likelihood of pursuing a scientific career (Stallmach et al., 2011; Houlden et al., 2004; Fang \& Meyer, 2003; Beck \& Depew, 2001).

At the University Medical Center in Hamburg (Germany), a new medical curriculum ("iMed Hamburg”) was developed, which officially started with the beginning of the winter term 2012. This newly designed curriculum offered the opportunity to implement a stronger focus on research and scientific methods in medicine throughout the course of studies. A new aspect in this curriculum is a mandatory research thesis at the end of the 10th term. This thesis is the endpoint of a chain of scientific modules, which are integrated longitudinally into the new curriculum. The first of these modules is a compulsory two-week introductory track on the basic principles of science, which every medical student in the first semester has to attend. During the further course of studies, students have the opportunity to select between different compulsory tracks. Main goal of our article is a detailed description of the development, implementation and evaluation of this introductory track.

\section{Description of the Project}

\subsection{Development of the Introductory Track}

In the newly designed and developed medical curriculum in Hamburg, every term is divided into three modules. The two-week introductory track into basic principles of science is placed in the middle of the first term, between the first and the third module. Likewise all other courses and classes in the iMed medical curriculum, participation is mandatory for all first-year medical students (about 380 students per year; each cohort is divided in 19 study groups of about 20 students each). 
The track was developed by a working group of scientists and physicians from different departments of the medical faculty (Anatomy, Biochemistry, Endocrinology, General Medicine, Legal Medicine, Medical Psychology, Medical Sociology, Neurophysiology, Occupational Medicine, Radio-Oncology, Tumour Biology) over the course of almost 2 years, mainly organized and coordinated by the authors. Based on consensus decision-making with all participants, an agreement on those basic principles of science in medicine was reached, that were to be integrated into the newly designed track. Basic principles included scientific theory and the research process, different types of epidemiological studies, ethics in medical science and finding, citing and critical appraisal of scientific publications. These principles were then translated into general learning objectives (see Table 1 and Table 2). Based on these learning objectives, lectures and classes were developed and then integrated into the track. Each of the lectures and classes was coordinated by a specialist with experience in the field, who also developed and compiled the respective materials such as presentations and articles or references. These specialists also organized trainings of the lecturers, which were held in the course of preliminary meetings. The materials were distributed among all lecturers in advance. By doing so, quality standards regarding the contents and the teaching of the classes were assured.

In order to foster interaction between students and lecturers, each study group was led by one lecturer throughout the two weeks. 19 lecturers from different departments were trained in order to teach the classes.

Table 1. Lectures in the introductory track.

\begin{tabular}{|c|c|c|}
\hline Lectures & $\begin{array}{l}\text { Learning objectives (examples) } \\
\text { Students are able to... }\end{array}$ & $\begin{array}{l}\text { Length } \\
\text { (min.) }\end{array}$ \\
\hline $\begin{array}{l}\text { Scientific theory and the research } \\
\text { process }\end{array}$ & $\begin{array}{l}\text {..explain basic scientific theories (e.g. falsification principle). } \\
\text {...differentiate phases of the research process. } \\
\text {...explain criteria for a causal relation. }\end{array}$ & 90 \\
\hline Types of epidemiological studies & $\begin{array}{l}\text {...differentiate types of observational studies. } \\
\text {...relate study types to different research aims. }\end{array}$ & 90 \\
\hline $\begin{array}{l}\text { Clinical trials and evidence-based } \\
\text { medicine }\end{array}$ & $\begin{array}{l}\text {...describe the basic understanding of evidence based medicine. } \\
\text {...describe different types of randomised studies and their scientific relevance. }\end{array}$ & 90 \\
\hline Ethics in science & $\begin{array}{l}\text {...critically assess scientific conduct. } \\
\text {...define plagiarism. } \\
\text {...name options to secure ethical standards. }\end{array}$ & 60 \\
\hline Ethics in medicine & $\begin{array}{l}\text {...describe ethical aspects in medicine. } \\
\text {...explain the relevance of moral standards such as "primum non nocere”. }\end{array}$ & 60 \\
\hline Research in medicine & $\begin{array}{l}\text {... assess the relevance of research in medicine. } \\
\text {...describe an example of actual research in medicine. }\end{array}$ & 60 \\
\hline
\end{tabular}

Table 2. Classes in the introductory track.

\begin{tabular}{cl}
\multicolumn{1}{c}{ Classes } & \multicolumn{1}{c}{$\begin{array}{c}\text { Learning objectives (examples) } \\
\text { Students are able to... }\end{array}$} \\
(min.)
\end{tabular}


Lectures were held by specialists in the respective field.

The final curriculum included 6 lectures and 6 classes, summing up to 29 teaching units of 45 minutes. Additionally, a lecture as an introduction to the track (90 minutes) was held and a presentation of all further topics in the compulsory modules, from which students are able to choose in the further course of studies (180 minutes). Each track was given the chance to present its topics and to promote its subjects. Also, free study and preparation time was included in the curriculum. The introductory track was finished with a multiple choice exam. The exam comprised 20 questions and lasted 30 minutes and it was developed based on the learning objectives (see as examples in Table 1 and Table 2). All lecturers participating in the development of the track had the opportunity to develop questions for the exam, which were then selected by the coordinators of the track based on their quality and applicability.

\subsection{Content of the Introductory Track}

Table 1 and Table 2 present a short overview over the objectives of the lectures and classes included in this introductory track.

The first lecture in the two-week track was on scientific theories and basic principles of the research process. Here, basic ideas of scientific thinking were introduced and important theoretical approaches were illustrated, such as the falsification principle, the principles of induction and deduction and the concept of causality. Furthermore, the research process, beginning with the development of a research question, the development and testing of hypotheses and the dissemination and utilisation of the results, was pointed out to the students.

We also included two lectures on different study designs in epidemiology and medicine. The first lecture included a short introduction of the history and a definition of epidemiology. In this lecture, two important types of observational studies including their advantages and disadvantages were discussed: the cohort study and the case-control study. The second lecture focused on clinical trials and evidence based medicine. After the introduction of key terms such as confounding, randomisation and blinding, the design of randomised controlled trials and examples were presented. Emphasis was put on the introduction of central ideas behind evidence based medicine.

As science in medicine is confronted with ethical problems, two lectures on the topic were included in the curriculum. A lecture on ethics in medicine discussed the importance of moral and ethical standards in medicine, on the background of the historic development of medicine. A lecture on ethics in science discussed the value of standards in science, especially in medical science. By showing examples of fallacy, scientific misconduct and plagiarism, the importance of ethical standards in medical science was demonstrated. Based on these examples possible ways for securing standards and preventing fallacy and plagiarism in science were discussed.

These two lectures were accompanied by a class, in which students had the opportunity to discuss ethical questions. Therefore, introductory theses on ethical issues were presented and then openly discussed by the students, as for example: "It is not possible to maintain the principle of non-maleficence in medicine when dealing with human experiments in medical research."

A lecture on "scientific research in medicine" was integrated in order to present highlights from clinical and preclinical research. In this lecture, outstanding scientists and researchers from various departments of the medical school get the opportunity to present their work, in order to illustrate the value and the attraction of research in medicine. For example in the winter term 2015/16 a colleague from the institute of systems neuroscience presented his research on chronic headache and migrane.

Two classes focussed on literature search. In the first class, the basics of literature search were taught. In addition, the principle of citation and correct ways of citing were demonstrated. Moreover, the importance of citation in science was discussed. The second class in collaboration with the medical library demonstrated the use of research tools and introduced different literature databases and library catalogues to the students.

After identifying and finding the literature, a class on scientific reading introduced students to the critical appraisal of scientific studies. Referring to the lecture on ethics in medical science and the lecture on epidemiology and study types in medicine, the basic structure of scientific publications was explained and key terms and concepts of medical studies such as blinding, randomisation and surrogate endpoints were introduced.

The introductory track was completed by a class on scientific presentation and a journal club. Students were introduced into the "dos and don'ts of scientific presentation", principles of visualisation and the structure of presentations. In the Journal Club students had the opportunity to read, reflect, present and discuss scientific pa- 
pers. These papers were preselected by the lecturers, with the premise to meet the level and interest of first term students. Main objective of this exercise was to apply the knowledge gathered in class and lectures and to outline the main characteristics and contents of the papers as well as discussing strengths and limitations of the studies.

\subsection{Evaluation of the Introductory Track}

An online evaluation was introduced at the end of each track. Each student had to pass the online evaluation process in order to get access to the results of the final exam. Thereby, a high return rate was achieved. The online evaluation assessed among others the satisfaction of students with lectures and classes specifically. General student satisfaction with motivation of the tutors, satisfaction with tuition in the track, the perception of recurrent themes in lectures and classes and the introduction into basic principles of science were assessed as well. A total of 1375 students participated in the online evaluation process (winter terms $2012 \mathrm{~N}=370,2013 \mathrm{~N}=366$, $2014 \mathrm{~N}=259,2015 \mathrm{~N}=380$ ). Due to a technical problem of the online evaluation system, in 2014/15 only 259 students were able to take part in the evaluation process. Response rates varied between $97 \%$ and $93 \%$ with the exception of 2014/15 where response rate reached only 66\%.

Results of the quantitative evaluation by the students showed high overall satisfaction (Table 3). Using a 6-point Likert-scale with higher values indicating higher satisfaction, mean satisfaction was 4.32 in 2012 and since then slightly rose to 4.59 in 2013 and 2014. When looking only at those students that agree with the respective items (i.e. rating it with 4 or higher), about 78 percent of the students were satisfied with the introductory track in 2012. In 2015 this rate was at 84 percent. Strongest agreement of the students was found for the item assessing lecturers' motivation: in 2012 the mean was 5.04 and in 2015 it slightly decreased to 4.98. Students also mostly agreed with the statement that the track was a good introduction into the basic principles of science ( $\mathrm{M}=4.47$ in 2012, $\mathrm{M}=4.65$ in 2015 respectively). Overall, the results indicate a slightly increasing student satisfaction with the introductory track, as most items show higher rates over time between the winter terms 2012 and 2015.

Meetings of all participating tutors and lecturers are held on a regulatory basis, at the beginning and at the end of each introductory track. Within these recorded meetings participants were asked for their general perception and appraisal of the introductory course and their satisfaction with content and development of the classes and lectures. A post processing discussion of all lecturers indicated that they generally were satisfied with the contents and the course of the introductory track. Especially the close relationship to the student cohort, which was built within these two weeks, was viewed as helpful. The working atmosphere was regarded as good and stimulating. Now four years after the implementation of the newly developed track, all lecturers report confidence in handling and teaching the contents. So far, there have been only few replacements of lecturers who were unable

Table 3. Means and standard deviation (SD) for selected items of student evaluation and rate of approval from four student cohorts (winter terms of 2012, 2013, 2014 and 2015); answers range from 1 "I totally disagree” to 6 "I totally agree”.

\begin{tabular}{|c|c|c|c|c|c|c|c|c|}
\hline & \multicolumn{2}{|c|}{$\begin{array}{l}\text { Cohort } 2012 \\
(\mathrm{~N}=370)\end{array}$} & \multicolumn{2}{|c|}{$\begin{array}{l}\text { Cohort } 2013 \\
(\mathrm{~N}=366)\end{array}$} & \multicolumn{2}{|c|}{$\begin{array}{l}\text { Cohort } 2014 \\
(\mathrm{~N}=259)\end{array}$} & \multicolumn{2}{|c|}{$\begin{array}{c}\text { Cohort } 2015 \\
(\mathrm{~N}=380)\end{array}$} \\
\hline Item & Mean (SD) & $\begin{array}{c}\text { Rate of } \\
\text { approval } \\
\text { (4 or better), } \\
\text { N (\%) }\end{array}$ & Mean (SD) & $\begin{array}{c}\text { Rate of } \\
\text { approval } \\
\text { (4 or better), } \\
\text { N (\%) }\end{array}$ & Mean (SD) & $\begin{array}{c}\text { Rate of } \\
\text { approval } \\
\text { (4 or better), } \\
\text { N (\%) }\end{array}$ & Mean (SD) & $\begin{array}{c}\text { Rate of } \\
\text { approval } \\
\text { (4 or better), } \\
\text { N (\%) }\end{array}$ \\
\hline $\begin{array}{l}\text { "With the tuition in this } \\
\text { track I am satisfied." }\end{array}$ & 4.32 (1.14) & $286(77)$ & 4.59 (1.10) & 315 (86) & 4.59 (1.09) & $226(87)$ & 4.44 (1.09) & 319 (84) \\
\hline $\begin{array}{l}\text { "Lecturers were motivated } \\
\text { for their teaching." }\end{array}$ & $5.04(1.03)$ & 339 (92) & $5.11(0.90)$ & 347 (95) & $5.13(0.86)$ & 247 (95) & $4.98(1.00)$ & $350(92)$ \\
\hline $\begin{array}{l}\text { "In this track a recurrent } \\
\text { theme over the lectures and } \\
\text { classes was observable.” }\end{array}$ & $4.45(1.07)$ & 307 (83) & 4.67 (0.97) & 329 (90) & 4.64 (1.05) & $228(88)$ & 4.54 (1.01) & 331 (87) \\
\hline $\begin{array}{l}\text { “This track was a good } \\
\text { introduction into the basic } \\
\text { principles of science.” }\end{array}$ & $4.47(1.07)$ & 305 (82) & $4.64(0.95)$ & 325 (89) & $4.67(0.90)$ & 230 (89) & 4.65 (1.01) & 334 (88) \\
\hline
\end{tabular}


to continue their teaching in the track, mostly due to organizational constraints.

\section{Discussion}

Implementation of an introductory track into the basic principles of science is intended to be the first step in preparing the students for their final thesis after the $10^{\text {th }}$ term and in furthering their knowledge on scientific skills. The longitudinal design of the newly developed curriculum enables all forthcoming scientific modules to recourse on the contents of the introductory track and thereby using these contents as a standard. Among others, the critical appraisal of studies and manuscripts, the presentation of scientific results and the writing of scientific papers will be part of forthcoming modules. This should allow a stronger consolidation of the knowledge gathered on scientific skills in the long-run, as it will be constantly repeated and intensified in the later course of studies, thereby enabling the transfer of knowledge gathered into different contexts (see also Norman, 2009). In how far knowledge can be retained on a long-run and transferred into different context (for example in following compulsory tracks, writing of final exams or medical dissertations) should be the goal of a longitudinal evaluation accompanying the students until the end of their studies.

The experiences described show that this introductory track can be a promising way to integrate basic principles of science into the medical curriculum (see also German Council of Science and Humanities, 2014). There were several factors we consider facilitating in terms of the successful implementation. 1) It was important that colleagues from different disciplines participated in the development and implementation process and that the track was considered a joint project. Regular meetings with all participating colleagues were held. This approach intensified cooperation between disciplines in the medical faculty by reaching an agreement on relevant basic principles of science in medicine. In the course of the development process different opinions on these principles were harmonized. Decisions on changes regarding the content of the introductory track were made together with all lecturers. For example, in the course of the first introductory track it became clear that most of the students were readily prepared regarding their abilities to hold presentations. Therefore, the respective class was shortened and revised. Similar is true for the journal club, which was established by the winter term 2013 in the course of active interaction of the lecturers in the track and has now been successfully repeated. There are still meetings of all lecturers and experts involved in the track on regular basis, in order to update and modify content if necessary. 2) Our experience indicates that a certain standardisation set by the presentations and lectures prepared by experts in the field and a specific training of the lecturers contributed to the successful implementation. All new lecturers participated in a one-day workshop, in which learning objectives were explained and relevant materials presented. Thereby it was assured that all testable content was taught in all study groups independent of the lecturer. Moreover, preparation time for lecturers was limited by providing all necessary materials for the classes on a web-based platform for educaters and learners (moodle), which contributed to a high overall satisfaction of lecturers with the track. 3) In our view, it was essential for the success of the track to implement it at an early stage of the medical curriculum as this helps sensitising students for the basic principles of science and allows the recapitulation and a consolidation of the principles in different contexts in the later course of studies.

\section{Conclusion}

The introductory track into the basic principles of science was established in the winter term of 2012 at the University Medical Center Hamburg, Germany. High overall satisfaction of the students is an indicator for a successful implementation of the introductory track into the medical curriculum. As most students in medicine seem to be rather interested in hands-on medicine, such a high satisfaction with the introduction into basic principles of science is not expected. Student satisfaction showed a slight increase over time: most items were rated higher in the winter term of 2015 than in 2012. This could be explained by the fact that tutors were more familiar with the contents and the structure of the introductory track than in the first year. Moreover, contents and presentations applied in the first year of the introductory track were revised to enhance understanding.

All further information beyond those given in the present article, especially on the details of the timetable and the content of the classes and lectures can be made accessible by the authors on demand.

\section{Acknowledgements}

Various colleagues from different departments and clinics of the University Medical Center Hamburg-Eppen- 
dorf contributed to the development of the introductory track. Therefore, the authors would like to acknowledge the contributions of the following colleagues: Norbert Sunderbrink (Medical Library), Eva Brinkschulte, Kai Sammet, Antje Zare, Heinz-Peter Schmiedebach (all Dept. of History in Medicine), Karl Wegscheider (Dept. of Medical Biometry and Epidemiology), Nina Egger (Dept. of Health Economics and Health Services Research), Christopher Kofahl, Daniel Lüdecke (Dept. of Medical Sociology), Marcial Velasco-Garrido (Institute for Occupational and Maritime Medicine), Eberhard Windler, Birgit C. Zyriax (both Clinic of Endocrinology), Annette Raabe (Dept. of Radiotherapy and Radio-Oncology), Volker Assmann, Steven A. Johnson, Klaus Pantel, Sabine Riethdorf (all Dept. of Tumorbiology), Sven Anders (Dept. of Legal Medicine), Evita Mohr (Department of Neuroanatomy), Ulrich Fickel (Department of Neurophysiology and Pathophysiology), Jelka Meyer (Office of Vice Dean of Education and Students' Affaires).

\section{Competing Interests}

The authors declare that they have no competing interests.

\section{References}

Aronoff, S. C., Evans, B., Fleece, D., Lyons, P., Kaplan, L., \& Rojas, R. (2010). Integrating Evidence Based Medicine Into Undergraduate Medical Education: Combining Online Instruction with Clinical Clerkships. Teaching and Learning in Medicine, 22, 219-223. http://dx.doi.org/10.1080/10401334.2010.488460

Beck, I. T., \& Depew, W. T. (2001). Canadian Research Fellowship Training Programs in Digestive Sciences: Achievements and Challenges. Clinical \& Investigative Medicine, 24, 44-53.

Fang, D., \& Meyer, R. E. (2003). Effect of Two Howard Hughes Medical Institute Research Training Programs for Medical Students on the Likelihood of Pursuing Research Careers. Academic Medicine, 78, 1271-1280. http://dx.doi.org/10.1097/00001888-200312000-00017

Fischer, M. R., \& Fabry, G. (2014). Thinking and Acting Scientifically: Indispensable Basis of Medical Education. GMS Journal for Medical Education, 31, Doc24.

German Council of Science and Humanities. [Empfehlungen zur Weiterentwicklung des Medizinstudiums in Deutschland auf Grundlage einer Bestandsaufnahme der humanmedizinischen Modellstudiengänge]. Dresden 2014.

Grande, J. P. (2009). Training of Physicians for the Twenty-First Century: Role of the Basic Sciences. Medical Teacher, 31, 802-806. http://dx.doi.org/10.1080/01421590903137049

Houlden, R. L., Jamila, R. B., Collier, C. P., Clark, A. F., \& Waugh, J. M. (2004). Medical Students’ Perceptions of an Undergraduate Research Elective. Medical Teacher, 26, 659-661. http://dx.doi.org/10.1080/01421590400019542

Lawson Maclean, A., Saunders, C., Velu, P.P., et al. (2013). Twelve Tips for Teachers to Encourage Student Engagement in Academic Medicine. Medical Teacher, 35, 549-554. http://dx.doi.org/10.3109/0142159X.2013.775412

Norman, G. (2009). Teaching Basic Science to Optimize Transfer. Medical Teacher, 31, 807-811. http://dx.doi.org/10.1080/01421590903049814

Pawlina, W. (2009). Basic Sciences in Medical Education: Why? How? When? Where? Medical Teacher, 31, 787-789. http://dx.doi.org/10.1080/01421590903183803

Siegrist, M., \& Giger, M. (2006). A Swiss Survey on Teaching Evidence-Based Medicine. Swiss Medical Weekly, 136, 776778.

Smeeton, N. (1997). Statistical Education in Medicine and Dentistry. Statistician, 46, 521-527. http://dx.doi.org/10.1111/1467-9884.00106

Spencer, A. L., Brosenitsch, T., Levine, A. S., \& Kanter, S. L. (2008). Back to the Basic Sciences: An Innovative Approach to Teaching Senior Medical Students How Best to Integrate Basic Science and Clinical Medicine. Academic Medicine, 83, 662-669. http://dx.doi.org/10.1097/ACM.0b013e318178356b

Stallmach, A., Bauer, M., Witte, O. W., \& Siegmund, B. (2011). Strategien zur Sicherung des wissenschaftlichen Nachwuchses. Deutsches Ärzteblatt, 108, 380-383.

van der Lee, N., Fokkema, J. P., Westermann, M., et al. (2013). The CanMEDS Framework: Relevant but Not Quite the Whole Story. Medical Teacher, 35, 949-955. http://dx.doi.org/10.3109/0142159X.2013.827329 